\title{
In vitro study of ultrasound and different-concentration glycerol-induced changes in human skin optical attenuation assessed with optical coherence tomography
}

\author{
Huiqing Zhong \\ Zhouyi Guo \\ Huajiang Wei \\ Changchun Zeng \\ Honglian Xiong \\ South China Normal University \\ Key Laboratory of Laser Life Science of Ministry \\ of Education of China \\ Guangzhou 510631, Guangdong \\ China
}

\section{Yonghong He}

Tsinghua University

Graduate School at Shenzhen

Shenzhen 518055, Guangdong

China

\section{Songhao Liu}

South China Normal University

Key Laboratory of Laser Life Science of Ministry of Education of China

Guangzhou 510631, Guangdong

China

\begin{abstract}
Previous studies have demonstrated the ultrasound-induced skin optical clearing enhancement with topical application of $60 \%$ glycerol $(\mathrm{G})$ on in vitro porcine skin and in vivo human skin. Our purpose was to find the relation between the effect of optical skin clearing and different concentrations of glycerol and to find more effective ultrasound-glycerol combinations on optical skin clearing. The enhancement effect of ultrasound [Sonophoresis (SP) delivery] in combination with $40 \% \mathrm{G}, 60 \% \mathrm{G}$, and $80 \% \mathrm{G}$ on in vitro human skin optical clearing was investigated. Light imaging depths of skin were measured using optical coherence tomography. Different concentrations of glycerol and ultrasound with a frequency of $1 \mathrm{MHz}$ and an intensity of $0.5 \mathrm{~W} / \mathrm{cm}^{2}$ was simultaneously applied for $15 \mathrm{~min}$. The results show that with the increase of concentration of glycerol, the optical clearing of skin is much improved. Optical clearing capability of glycerol was more enhanced with simultaneous application of ultrasound compared with glycerol alone. The attenuation coefficients of skin tissues after application of $40 \% \mathrm{G} / \mathrm{SP}, 60 \% \mathrm{G} / \mathrm{SP}$, and $80 \%$ $\mathrm{G} / \mathrm{SP}$ decreased approximately $11.8 \%, 18.5 \%$, and $20.0 \%$ at $15 \mathrm{~min}$ compared with $40 \% \mathrm{G}, 60 \% \mathrm{G}$, and $80 \%$ G alone, respectively. The greatest decrease in attenuation coefficients at 60 min was approximately $52.3 \%$ and $63.4 \%$ for $80 \%$ G (without ultrasound) and $80 \%$ $\mathrm{G} / \mathrm{SP}$ (with ultrasound), respectively, which are 2.1 -fold and 2.6 -fold to that in the $40 \%$ G. $\odot 2010$ Society of Photo-Optical Instrumentation Engineers. [DOl: $10.1117 / 1.3432750]$
\end{abstract}

Keywords: skin; optical attenuation; optical skin clearing; attenuation coefficient; glycerol; ultrasound.

Paper 09472R received Oct. 18, 2009; revised manuscript received Mar. 8, 2010 accepted for publication Apr. 6, 2010; published online Jun. 3, 2010.

\section{Introduction}

Engineered tissue optics is a new research area that allows reversibly altering light scattering and absorption within naturally turbid tissues in a precise and controlled manner. ${ }^{1}$ Tissue optical clearing permits delivery of near-collimated light deeper into tissue, potentially improving the capabilities of various optical diagnostic and therapeutic techniques such as new light-based therapies for reshaping or removing adipose tissue. ${ }^{1}$ The effects of optical clearing of highly scattering biological tissue by using the optical clearing agents (OCAs)-e.g., glycerol $(\mathrm{G}),{ }^{2-4}$ glucose, ${ }^{5-7}$ and dimethyl sulfoxide ${ }^{8,9}$ - have been investigated using many techniques, examples of which include near-infrared (NIR) spectrophotometers ${ }^{10,11}$ and optical coherence tomography (OCT) imaging. ${ }^{12-17}$ OCT is a recently developed imaging technique that has the potential for early diagnosis of diseases in human tissues. ${ }^{18,19}$ It has very high axial resolution, but the

Address all correspondence to: Huajiang Wei, Key Laboratory of Laser Life Science of Ministry of Education of China, South China Normal University, Guangzhou 510631, Guangdong, China. Tel: +86-20-85217070-8603; Fax: +86-2085216052; E-mail: weihj@scnu.edu.cn high scattering nature of nontransparent human tissue limits the imaging depth of OCT to 1 to 2 millimeters. Although the depth of light penetrations of biotissue can be effectively increased by OCAs, however, the outermost layer of the skin, the stratum corneum (SC), presents a significant barrier to the most topically applied OCAs and is hence responsible for the poor optical clearing effect. ${ }^{17,20,21}$ To reduce barrier function of skin tissues during optical clearing, many different chemical and physical methods have been proposed. Chemical penetration enhancers, ${ }^{22}$ photothermal, ${ }^{23,24}$ sandpaper, ${ }^{25}$ microneedle, ${ }^{26,27}$ electroporation, ${ }^{28}$ iontophoresis, ${ }^{29}$ tape stripping, ${ }^{30}$ laser ablation, ${ }^{31}$ ultrasound [sonophoretic (SP) delivery,${ }^{32-36}$ and jet injection have been shown to accelerate the skin permeability of OCAs. ${ }^{22}$ Recent investigation indicated that sonophoretic delivery, as a noninvasive physical method, exhibited an enhancing skin clearing effect when applied topically with OCAs. ${ }^{16-18}$ Significant ultrasoundinduced enhancement in OCT imaging depth and contrast of in vitro porcine skin and in vivo human skin was found, ${ }^{16,18}$ but it was just research on $60 \%$ glycerol in combination with

1083-3668/2010/15(3)/036012/7/\$25.00 @ $2010 \mathrm{SPIE}$ 
Zhong et al.: In vitro study of ultrasound and different-concentration glycerol-induced changes...

Table 1 Treatment in this study.

\begin{tabular}{lccccc}
\hline Treatment & Glycerol & Distilled water & Ultrasound (SP) & Refractive index (n) & Cases \\
\hline $40 \%$ G & 40 & 60 & - & 1.3941 & 6 \\
$40 \%$ G/SP & 40 & 60 & + & 1.3941 & 6 \\
$60 \%$ G & 60 & 40 & - & 1.4190 & 6 \\
$60 \%$ G/SP & 60 & 40 & + & 1.4190 & 6 \\
$80 \%$ G & 80 & 20 & + & 1.4494 & 6 \\
$80 \%$ G/SP & 80 & 20 & + & 1.4494 & 6 \\
\hline
\end{tabular}

ultrasound. In this study, we use the attenuation coefficients within the skin tissues to evaluate the optical skin clearing change after topical application of different concentrations of glycerol and compare with different concentrations of glycerol in combination with 15 -min ultrasound at various time intervals of $0,15,30,45$, and $60 \mathrm{~min}$, respectively. The aim of this investigation is to find the relation between effect of optical skin clearing and different concentrations of glycerol and explore a more effective method for skin optical clearing than pure OCAs.

\section{Materials and Methods}

\subsection{Tissue Preparation}

A total of 36 normal human skin tissue samples were taken from the abdominal skin tissue of 36 human subjects immediately after surgical excision of subcutaneous fatty tissue. Each tissue sample was immediately rinsed briefly in saline to remove excess surface blood after the excision. Then, the tissue sample was placed in a bottle with saline as soon as possible, sealed to prevent natural dehydration, and stored in a refrigerator at $-70^{\circ} \mathrm{C}$. Each skin sample was cut into $27.5 \mathrm{~mm} \times 27.5 \mathrm{~mm}$ samples by microtome before measurement (the mean thickness of samples was $(1.83 \pm 0.05) \mathrm{mm}$ ) and then thawed to room temperature $\left(25^{\circ} \mathrm{C}\right)$.

\subsection{OCT System}

The OCT system used in this study consists mainly of resource module, fiber conduction module, reference arms module, and sample arms module. A schematic of the OCT system was shown in the literature. ${ }^{37}$ The broadband light source is a superluminescent diode with a central wavelength at $1310 \mathrm{~nm}$ and a bandwidth of $50 \mathrm{~nm}$. The light source yields a $15-\mu \mathrm{m}$ axial resolution in free space, or approximately $10 \mu \mathrm{m}$ in tissue, as the mean refractive index of bulk tissue is assumed to be 1.38. The transverse resolution of the system is about $25 \mu \mathrm{m}$, as determined by the focal spot size produced by the probe beam. The signal-to-noise ratio (SNR) of this system is measured at $100 \mathrm{~dB}$. A visible light source $(\lambda=645 \mathrm{~nm})$ was used to guide the probe beam. The OCT system operation is controlled automatically by computer. The detector current is demodulated using a lock-in amplifier and a low-pass filter in software prior to storage. Each in-depth scanning (A-scan) consists of 10,000 data points. The lateral scanning (B-scan) image is obtained by moving the mirror relative to the tissue sample, which takes about $1.0 \mathrm{~s}$. The data acquisition software is written in LabView 7.2-D. OCT images are obtained in each experiment and stored on the PC for further processing. ${ }^{37,38}$

\subsection{Ultrasound and Glycerol Application}

A BM628 sonicator with a 0.8-cm-diam probe (Guangzhou Radium Cosmetic Co. Ltd., Guangzhou, China) was used. The ultrasound frequency and intensity were 1 to $1.1 \mathrm{MHz}$ and $0.5 \mathrm{~W} / \mathrm{cm}^{2}$, respectively. Sonicators with this frequency are most commonly used in cosmetic treatments and transdermal drug delivery (TDD).

Glycerol (with $99.9 \%$ concentration) was purchased from the Tianjin Damao Chemical Reagent Factory (China). The concentration of the glycerol solutions used in this study was reduced to $40 \%, 60 \%$, and $80 \%$ through mixing the agents with distilled water (vol/vol). For the glycerol-ultrasound groups, solutions of $40 \%, 60 \%$, and $80 \%$ glycerol were applied to the surface of each skin sample, respectively, and ultrasound was simultaneously performed on these samples for a period of $15 \mathrm{~min}$, respectively. During ultrasound treatment, the ultrasound probe was immersed in the glycerol solution that was topically applied to the surface of skin. After the 15-min ultrasound treatment, the sample was kept occluded with solution for a total of $60 \mathrm{~min}$. The optical clearing agents and ultrasound treatments are listed in Table 1.

\subsection{Normalized Intensity Profiles and Attenuation Coefficient}

The OCT normalized intensity profiles were obtained by averaging the linearized signal intensity across the lateral imaging range as a function of depth. A best-fit exponential curve covering the epidermis and dermis in depth was applied to the averaged data of each group.

OCT imaging is based on the difference of backscattered light. The result is the measurement of optical backscattering or reflectance, $R(z)$, versus axial ranging distance, or depth, $z$. The reflectance depends on the optical properties of tissuei.e., the absorption $\left(\mu_{a}\right)$ and scattering $\left(\mu_{s}\right)$ coefficients, or total attenuation coefficient $\left(\mu_{t}\right), \mu_{t}=\mu_{a}+\mu_{s}$ (Ref. 39). The relationship between $R(z)$ and $\mu_{t}$ is, however, very complicated due to the high-scattering nature of biological tissue. However, for relatively transparent tissue, the reflected power 


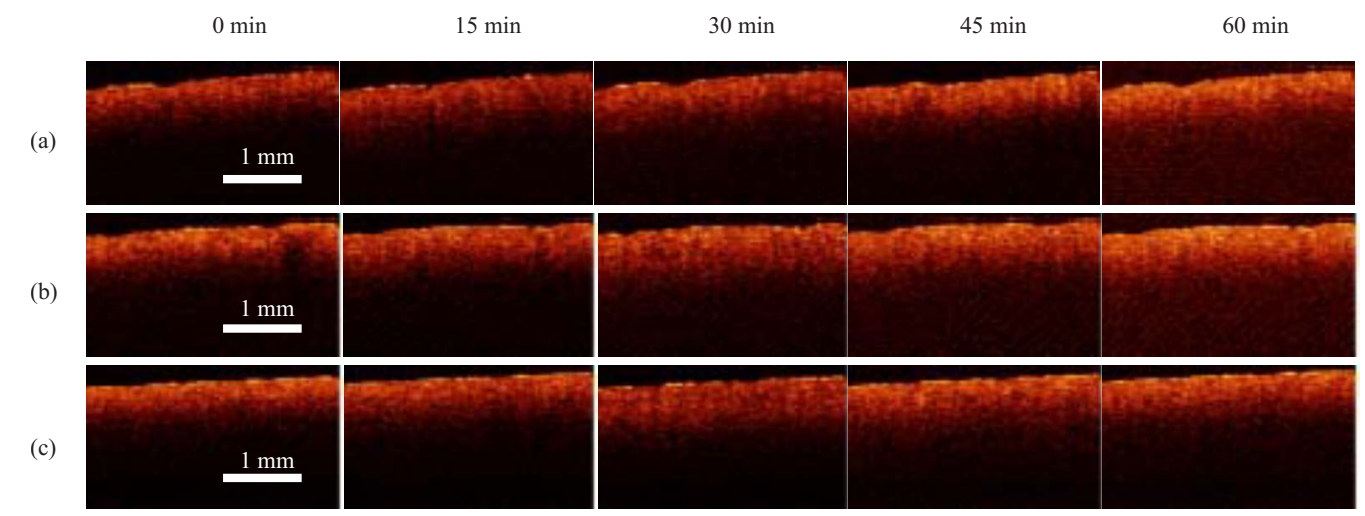

Fig. 1 OCT images of skin tissue at 0, 15, 30, 45, and 60 min (from right to left) after topical application of (a) 40\% G, (b) 60\% G, and (c) 80\% $\mathrm{G}$ alone, respectively.

will be negatively proportional to $2 \mu_{t} z$ in exponential scale according to the single scattering model, which is valid for an optical depth less than 4 (Refs. 39 and 40):

$$
R(z)=I_{0} \times T(z) \times \exp \left(-2 \mu_{t} z\right),
$$

where $I_{0}$ is the light intensity launched into the tissue sample, and $T(z)$ is the reflectivity of the tissue at depth $z$. The factor of 2 in the exponential accounts for the light passing through the tissue twice after being backscattered. It should be noted that the optical depth is a measure of the depth in terms of the number of mean free path lengths-i.e., $\mu_{s} z$ (Ref. 39). $T(z)$ is linked to the local refractive index and backscattering property of the tissue. ${ }^{41-43}$ However, for a homogenous turbid medium, it can be considered to be constant. Therefore, $\mu_{t}$ can be obtained theoretically from the reflectance measurements at two different depths, $z_{1}$ and $z_{2}$ (Ref. 39):

$$
\mu_{t}=\frac{1}{2(\Delta z)} \ln \left[\frac{R\left(z_{1}\right)}{R\left(z_{2}\right)}\right],
$$

where $\Delta z=\left|z_{1}-z_{2}\right|$. As noise is inevitable in the measurement, a final result should thus be obtained by the use of a leastsquares fitting technique in order to improve the accuracy of the determined value of $\mu_{t}$. The total attenuation coefficients of light through skin tissues are calculated by Eq. (2).

Reduction of attenuation coefficients $\Delta \mu_{t}$ by the solutions at the time intervals of treatment were calculated according to

$$
\Delta \mu_{t}=\frac{\mu_{t(\text { treated })}-\mu_{t(\text { control })}}{\mu_{t(\text { control })}} \times 100 \%,
$$

where $\mu_{t}$ is the attenuation coefficient. The subscripts control and treated refer to the samples before $(0 \mathrm{~min})$ and after the application of agents at the different time intervals, respectively.

\subsection{Statistical Analysis}

The data from all samples were presented as means \pm SD and analyzed by an SPSS 10.0 software paired-test. The $p$ $<0.05$ value indicated significant difference.

\section{Results and Discussion}

\subsection{Without Ultrasound}

Figures 1(a)-1(c) are the OCT images of in vitro human skin at $0,15,30,45$, and $60 \mathrm{~min}$ after topical application of $40 \%$ $\mathrm{G}, 60 \% \mathrm{G}$, and $80 \% \mathrm{G}$ alone, respectively. It can be seen that light penetration is limited in native skin (see Fig. 1; 0 min). It is shown that structural features within the skin are more visualized with the increase of time after different treatments, and the light penetration was enhanced, as the light can be seen coming back from the deeper skin with the increase of time after treatment. The high-concentration solutions induce more transparency of skin than the surroundings, so the clearing capability of $80 \% \mathrm{G}$ was most improved over that of $40 \%$ $\mathrm{G}$ and $60 \% \mathrm{G}$ alone, whereas $40 \% \mathrm{G}$ has the lowest clearing effect (Fig. 1). This means that with the increase of concentration of glycerol, the optical clearing of skin is more improved. The results obtained were similar to these of Mao et al., who have demonstrated more optical skin clearing improvement than that with low-concentration glycerol injected into the dorsal dermas of SD rat from reflectance spectra. ${ }^{44}$

\subsection{With Ultrasound}

The dynamics of enhancement in OCT normalized intensity profiles with corresponding exponential best-fit curves of skin at 0,15 , and $30 \mathrm{~min}$ after topical application of $40 \% \mathrm{G} / \mathrm{SP}$, $60 \% \mathrm{G} / \mathrm{SP}$, and $80 \% \mathrm{G} / \mathrm{SP}$ are shown in Fig. 2. It can be seen from Fig. 2 that due to enhanced light transport within the skin tissue, more light propagates to the reflective surface underneath the skin tissue, giving rise to a stronger backreflected signal in the OCT amplitude data. The degree of change increases with the increase of concentration of glycerol, meaning that the largest increases in the OCT normalized intensity profiles of skin after treatment occur with $80 \%$ $\mathrm{G} / \mathrm{SP}$ rather than that of $40 \% \mathrm{G} / \mathrm{SP}$ and $60 \% \mathrm{G} / \mathrm{SP}$ over the same time [Figs. 2(a)-2(c)].

\subsection{Without and with Ultrasound}

Figure 3 summarizes the attenuation coefficients of skin tissue at $0,15,30,45$, and $60 \mathrm{~min}$ after topical application of (a) $40 \% \mathrm{G}, 60 \% \mathrm{G}$, and $80 \% \mathrm{G}$ (without ultrasound) and (b) $40 \%$ $\mathrm{G} / \mathrm{SP}, 60 \% \mathrm{G} / \mathrm{SP}$, and $80 \% \mathrm{G} / \mathrm{SP}$ (with ultrasound), respec- 


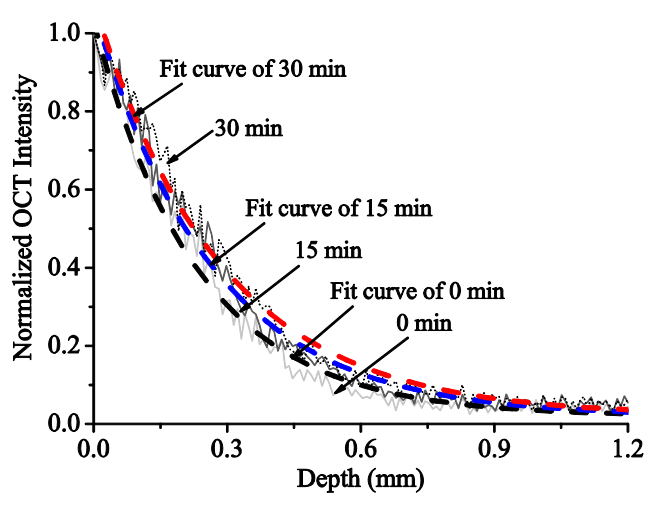

(a)

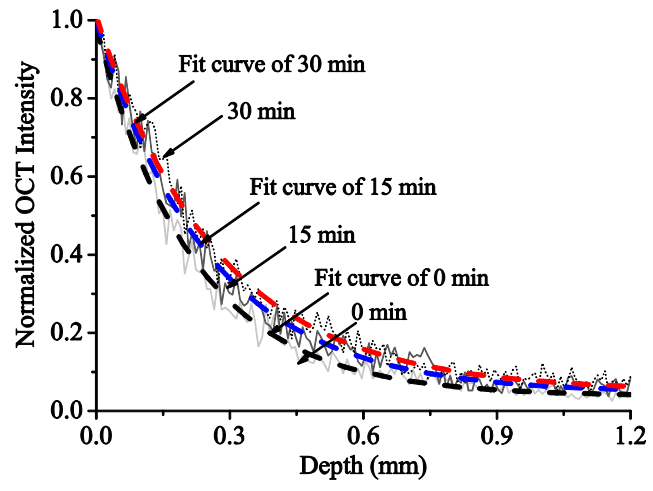

(b)

(c)

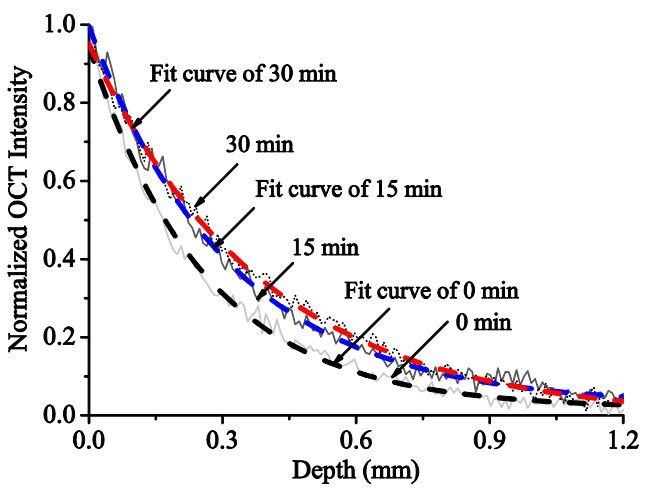

Fig. 2 OCT normalized intensity profiles with corresponding exponential best-fit curves of in vitro human skin at 0, 15, and 30 min after topical application. (a) $40 \% \mathrm{G} / \mathrm{SP}$, (b) $60 \% \mathrm{G} / \mathrm{SP}$, and (c) $80 \% \mathrm{G} / \mathrm{SP}$.

tively. It can be seen from Fig. 3 that not only without ultrasound, but also with ultrasound, the light attenuation coefficients of skin tissue decrease with the increase of time after topical application-e.g., for $40 \% \mathrm{G} / \mathrm{SP}$, the light attenuation coefficients of skin tissue are 1.97, 1.49, 1.32, 1.29, and $1.26 \mathrm{~mm}^{-1}$ at $0,15,30,45$, and $60 \mathrm{~min}$, respectively. It also can be seen that the attenuation coefficients of skin tissue at the same times decreases with the increase of concentration of glycerol. For example, the attenuation coefficients of skin tis- sue at 15 min after topical application of $40 \% \mathrm{G}, 60 \% \mathrm{G}$, and $80 \% \mathrm{G}$ alone are $(1.69 \pm 0.05),(1.58 \pm 0.04)$, and $(1.41 \pm 0.04) \mathrm{mm}^{-1}$, respectively; the light attenuation coefficients of skin tissue at 15 min after treatment with of $40 \%$ $\mathrm{G} / \mathrm{SP}, \quad 60 \% \mathrm{G} / \mathrm{SP}$, and $80 \% \mathrm{G} / \mathrm{SP}$ are $(1.49 \pm 0.04)$, $(1.28 \pm 0.03)$ and $(1.14 \pm 0.03) \mathrm{mm}^{-1}$, respectively. These results agree with previous research that the glycerol solutions with high concentration induced much decreased reflectance,

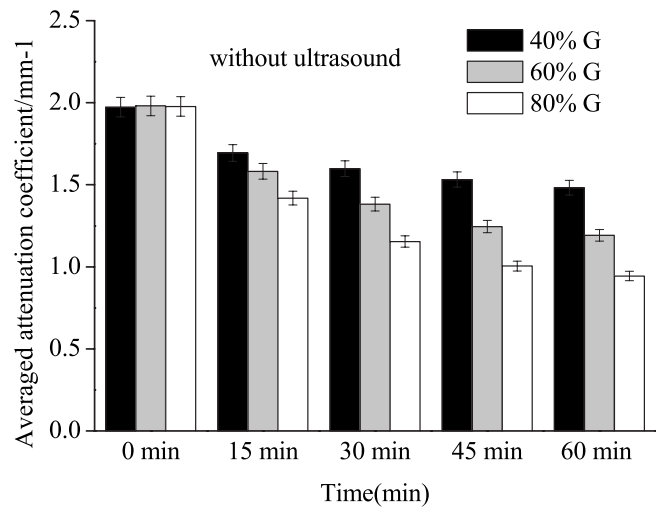

( a )

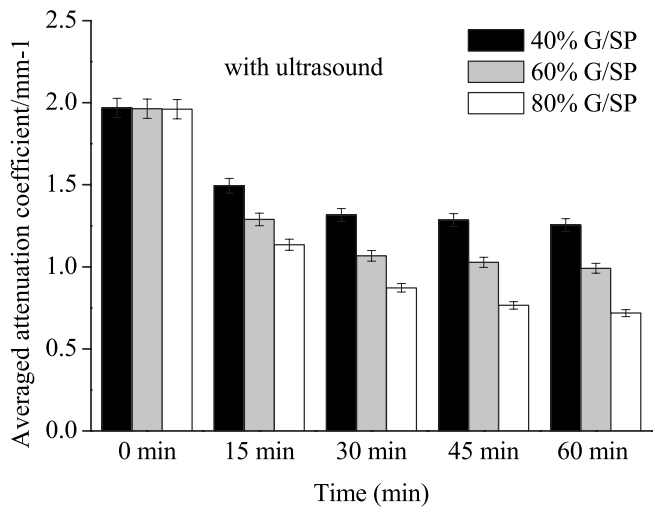

( b )

Fig. 3 Attenuation coefficients of skin tissues at 0, 15, 30, 45, and 60 min after topical application of (a) 40\% G, 60\% G, 80\% G alone (without ultrasound) and (b) $40 \% \mathrm{G} / \mathrm{SP}, 60 \% \mathrm{G} / \mathrm{SP}, 80 \% \mathrm{G} / \mathrm{SP}$ (with ultrasound). 


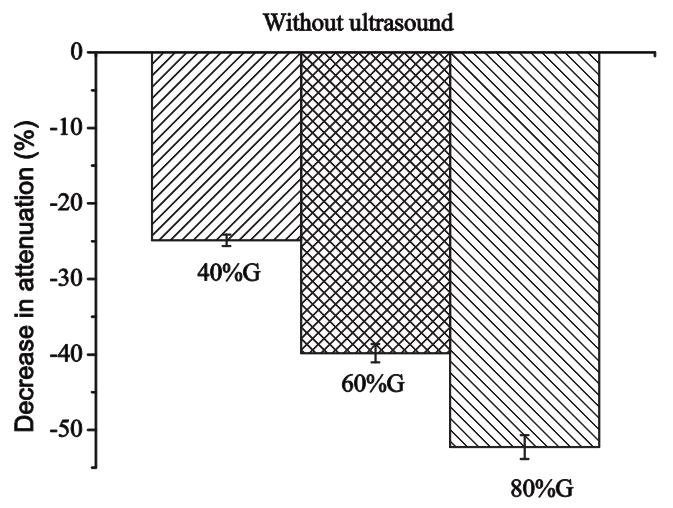

(a)

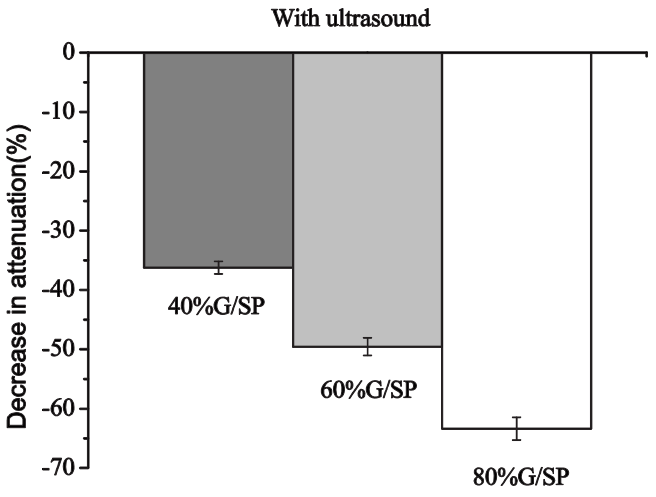

(b)

Fig. 4 Attenuation reduction in human skins induced by different concentrations of glycerol and (a) without ultrasound and (b) with ultrasound.

which means that the $\mu_{s}$ of tissue decayed a lot and the skin became much optical clearing. ${ }^{45,46}$ Comparing glycerolultrasound group with the same concentration of glycerol alone group, the attenuation coefficients of skin tissue after application of $40 \% \mathrm{G} / \mathrm{SP}$, and $60 \% \mathrm{G} / \mathrm{SP}$, and $80 \% \mathrm{G} / \mathrm{SP}$ decreased approximately $11.8 \%, 18.5 \%$, and $20.0 \%$ at $15 \mathrm{~min}$ over that of $40 \% \mathrm{G}, 60 \% \mathrm{G}$, and $80 \% \mathrm{G}$ alone, respectively. This means that there is a large change in the attenuation coefficients with ultrasound and without ultrasound. It also clearly demonstrates the enhancement of optical skin clearing when ultrasound is applied. This phenomenon is consistent with previous findings that ultrasound caused the increase of cell membrane permeability in TDD. ${ }^{47-50}$

The quantitative reductions of attenuation coefficients at 60 min according to Eq. (3) for skin samples under different treatment procedures $(40 \% \mathrm{G}, 60 \% \mathrm{G}, 80 \% \mathrm{G}, 40 \% \mathrm{G} / \mathrm{SP}$, $60 \%$ G/SP, and $80 \%$ G/SP) are shown in Figs. 4(a) and 4(b), respectively. The greatest decreases in attenuation coefficients were approximately $52.3 \%$ and $63.4 \%$ for $80 \% \mathrm{G}$ (without ultrasound) and $80 \% \mathrm{G} / \mathrm{SP}$ (with ultrasound), respectively, which are 2.1-fold and 2.6-fold that in the $40 \% \mathrm{G}$ at $60 \mathrm{~min}$. The differences in enhancement in transmission of skin tissue are significant between $60 \% \mathrm{G}$ and $40 \% \mathrm{G}$ at $30 \mathrm{~min}(P$ $<0.05)$; between $80 \% \mathrm{G}$ and $60 \% \mathrm{G}$ at $30 \mathrm{~min}(P<0.05)$; between $60 \% \mathrm{G} / \mathrm{SP}$ and $40 \% \mathrm{G} / \mathrm{SP}$ at $30 \mathrm{~min}(P<0.05)$; between $80 \% \mathrm{G} / \mathrm{SP}$ and $60 \% \mathrm{G} / \mathrm{SP}$ at $30 \mathrm{~min}(P<0.05)$; between $40 \% \mathrm{G} / \mathrm{SP}$ and $40 \% \mathrm{G}$ at $15 \mathrm{~min}(P<0.05)$; between $60 \% \mathrm{G} / \mathrm{SP}$ and $60 \% \mathrm{G}$ at $15 \mathrm{~min}(P<0.05)$; and between $80 \% \mathrm{G} / \mathrm{SP}$ and $80 \% \mathrm{G}$ at $15 \mathrm{~min}(P<0.05)$. Figures 3 and 4 clearly demonstrate that there is a more obvious enhancement effect for skin optical clearing when ultrasound is applied than that without ultrasound. These results are consistent with Xu's findings of in vitro porcine skin clearing enhancement of $60 \%$ glycerol in combination with ultrasound. ${ }^{16-18,51}$

Ultrasound has demonstrated an enhancing transdermal mass transport effect when applied topically in TDD. Its mechanism is believed to be through acoustic cavitation, which is the formation and collapse of gaseous cavities, and has the dominant role in sonophoresis. ${ }^{52,53}$ Based on the aforementioned results, it indicated that due to ultrasound's penetration enhancing and convection effect, more glycerol can penetrate the skin tissues and glycerol can penetrate more quickly to achieve more refractive index matching in human skin tissue in vitro to improve skin tissue optical clearing.

It is necessary to note that the diffusion of glycerol in human skin tissue will change the refractive index during the course of the experiment and therefore will affect the size of the region selected for calculations. But this alteration in tissue optical size was small enough and was neglected in our computation. Also, biological tissue is a turbid nonuniform tissue with some variations in the refractive indexes through its layers. ${ }^{54}$

\section{Conclusion}

We have summarized the optical clearing of human skin after application of different-concentration glycerol and analyzed the difference effect in optical skin clearing after treatment with ultrasound and without ultrasound. The results reported here indicate that glycerol with high concentration can markedly enhance optical clearing of skin. But it was confirmed that simultaneous application of ultrasound and glycerol led to an obvious increase in light transmission and imaging depth through in vitro human skin. Our future studies will be focused on increasing knowledge of the mechanisms for synergistic effect of ultrasound and glycerol by microscopy or other advanced techniques. There is a stronger correlation with insonation frequency and power density, and there is a difference between in vivo and in vitro skin; therefore, in order to more safely and effectively improve optical skin tissue clearing, future studies should also focus on these correlations.

\section{Acknowledgments}

This work was supported by the National Natural Science Foundation of China (Grant No. 60778047), the Natural Science Foundation of Guangdong Province (Grant No. 06025080), the Key Science and Technology Project of Guangdong Province of China (Grant No. 2005B50101015 and Grant No. 2008B090500125), and the Key Science and Technology Project of Guangzhou City of China (Grant No. 2008Z1-D391).

\section{References}

1. C. G. Rylander, T. E. Milner, S. A. Baranov, and J. S. Nelson, "Mechanical tissue optical clearing devices: enhancement of light penetration in ex vivo porcine skin and adipose tissue," Lasers Surg. Med. 40(10), 688-694 (2008). 
2. J. Jiang, M. Boese, P. Turner, and R. K. Wang, "Penetration kinetics of dimethyl sulphoxide and glycerol in dynamic optical clearing of porcine skin tissue in vitro studied by Fourier transform infrared spectroscopic imaging," J. Biomed. Opt. 13(2), 021105 (2008).

3. D. Zhu, J. Zhang, H. Cui, Z. Mao, P. Li, and Q. Luo, "Short-term and long-term effects of optical clearing agents on blood vessels in chick chorioallantoic membrane," J. Biomed. Opt. 13(2), 021106 (2008).

4. R. J. McNichols, M. A. Fox, A. Gowda, S. Tuya, B. Bell, and M. Motamedi, "Temporary dermal scatter reduction: quantitative assessment and implications for improved laser tattoo removal," Lasers Surg. Med. 36(4), 289-296 (2005).

5. M. Kinnunen, R. Myllylä, and S. Vainio, "Detecting glucose-induced changes in in vitro and in vivo experiments with optical coherence tomography," J. Biomed. Opt. 13(2), 021111 (2008).

6. A. N. Bashkatov, A. N. Korolevich, V. V. Tuchin, Y. P. Sinichkin, E. A. Genina, M. M. Stolnitz, N. S. Dubina, S. I. Vecherinski, and M. S. Belsley, "In vivo investigation of human skin optical clearing and blood microcirculation under the action of glucose solution," Asian J. Phys. 15(1), 1-14 (2006)

7. R. K. Wang, X. Q. Xu, J. B. Elder, and V. V. Tuchin, "Possible mechanisms for optical clearing of whole blood by dextrans," Proc. SPIE 4965, 84-94 (2003).

8. Y. H. He and R. K. Wang, "Dynamic optical clearing effect of tissue impregnated with hyperosmotic agents and studied with optical coherence tomography," J. Biomed. Opt. 9(1), 200-206 (2004).

9. W. K. den Otter, R. Notman, J. Anwar, M. G. Noro, and W. J. Briels, "Modulating the skin barrier function by DMSO: molecular dynamics simulations of hydrophilic and hydrophobic transmembrane pores," Chem. Phys. Lipids 154(Suppl. 1), S2-S3 (2008).

10. J. Jiang, L. Zhang, and R. K. Wang, "Synergistic effect of hyperosmotic agents under topical application on optical clearing of skin tissue in vitro," Proc. SPIE 5696, 80-90 (2005).

11. X. Xu, R. K. Wang, J. B. Elder, and V. V. Tuchin, "Effect of dextraninduced changes in refractive index and aggregation on optical properties of whole blood," Phys. Med. Biol. 48(9), 1205-1221 (2003).

12. H. Liu, B. Beauvoit, M. Kimura, and B. Chance, "Dependence of tissue optical properties on solute-induced changes in refractive index and osmolarity," J. Biomed. Opt. 1(2), 200-211 (1996).

13. V. V. Tuchin, X. Xu, and R. K. Wang, "Dynamic optical coherence tomography in studies of optical clearing, sedimentation, and aggregation of immersed blood," Appl. Opt. 41(1), 258-271 (2002).

14. R. K. Wang, X. Xu, V. V. Tuchin, and J. B. Elder, "Concurrent enhancement of imaging depth and contrast for optical coherence tomography by hyperosmotic agents," J. Opt. Soc. Am. B 18(7), 948953 (2001).

15. R. K. Wang and J. B. Elder, "Propylene glycerol as a contrasting agent for optical coherence tomography to image gastrointestinal tissues," Lasers Surg. Med. 30(3), 201-208 (2002).

16. X. Xu and Q. Zhu, "Sonophoretic delivery for contrast and depth improvement in skin optical coherence tomography," IEEE J. Sel. Top. Quantum Electron. 14(1), 56-61 (2008).

17. X. Xu, Q. Zhu, and C. Sun, "Combined effect of ultrasound-SLS on skin optical clearing," IEEE Photonics Technol. Lett. 20(24), 21172119 (2008).

18. X. Xu and Q. Zhu, "Feasibility of sonophoretic delivery for effective skin optical clearing," IEEE Trans. Biomed. Eng. 55(4), 1432-1437 (2008).

19. G. J. Tearney, M. E. Brezinski, B. E. Bouma, S. A. Boppart, C. Pitris, J. F. Southern, and J. G. Fujimoto, "In vivo endoscopic optical biopsy with optical coherence tomography," Science 276(5231), 2037-2039 (1997).

20. S. J. Marrink and H. J. C. Berendsen, "Permeation process of small molecules across lipid membranes studied by molecular dynamics simulations," J. Phys. Chem. 100(41), 16729-16738 (1996).

21. M. R. Prausnitz, S. Mitragotri, and R. Langer, "Current status and future potential of transdermal drug delivery," Nat. Rev. Drug Discovery 3(2), 115-124 (2004).

22. V. V. Tuchin, "A clear vision for laser diagnostics (review)," IEEE J. Sel. Top. Quantum Electron. 13(6), 1621-1628 (2007)

23. V. V. Tuchin, G. B. Altshuler, A. A. Gavrilova, A. B. Pravdin, D. Tabatadze, J. Childs, and I. V. Yaroslavsky, "Enhanced optical clearing of human skin at topical application of immersion agents to stratum corneum pretreated by a lattice-like photothermal ablation,' Proc. SPIE 6078, 60780V (2006).

24. V. V. Tuchin, G. B. Altshuler, A. A. Gavrilova, A. B. Pravdin, D.
Tabatadze, J. Childs, and I. V. Yaroslavsky, "Optical clearing of skin using flashlamp-induced enhancement of epidermal permeability," Lasers Surg. Med. 38(9), 824-836 (2006).

25. O. Stumpp, B. Chen, and A. J. Welch, "Using sandpaper for noninvasive transepidermal optical skin clearing agent delivery," $J$. Biomed. Opt. 11(4), 041118 (2006).

26. J. Yoon, T. Son, E. Choi, B. Choi, J. S. Nelson, and B. Jung, "Enhancement of optical skin clearing efficacy using a microneedle roller," J. Biomed. Opt. 13(2), 021103 (2008).

27. S. Henry, D. V. McAllister, M. G. Allen, and M. R. Prausnitz, "Microfabricated microneedles: a novel approach to transdermal drug delivery," J. Pharm. Sci. 87(8), 922-925 (1998).

28. A. Sharma, M. Kara, F. R. Smith, and T. R. Krishnan, "Transdermal drug delivery using electroporation. I. Factors influencing in vitro delivery of terazosin hydrochloride in hairless rats," J. Pharm. Sci. 89(4), 528-535 (2000).

29. Y. Pan, H. Zhao, and J. Zheng, "The enhancing effect of electroporation and iontophoresis on the permeation of insulin through human skin," Acta Pharmacol. Sin. 37, 649-652 (2002) (in Chinese).

30. S. J. Bashir, A. L. Chew, A. Anigbogu, F. Dreher, and H. I. Maibach, "Physical and physiological effects of stratum corneum tape stripping," Skin Res. Technol. 7(1), 40-48 (2001).

31. J. S. Nelson, J. L. Mccullough, T. C. Glenn, W. H. Wright, L. L. Liaw, and S. L. Jacques, "Mid-infrared laser ablation of stratum corneum enhances in vitro percutaneous transport of drugs," J. Invest. Dermatol. 97(5), 874-879 (1991).

32. C. Y. Huang, B. Liu, and M. E. Brezinski, "Ultrasound-enhanced optical coherence tomography: improved penetration and resolution," J. Opt. Soc. Am. A 25(4), 938-946 (2008).

33. A. H. El-Kamel, I. M. Al-Fagih, and I. A. Alsarra, "Effect of sonophoresis and chemical enhancers on testosterone transdermal delivery from solid lipid microparticles: an in vitro study," Curr. Drug Deliv. 5(1), 20-26 (2008).

34. J. Kushner IV, D. Kim, P. T. C. So, D. Blankschtein, and R. S Langer, "Dual-channel two-photon microscopy study of transdermal transport in skin treated with low-frequency ultrasound and a chemical enhancer," J. Invest. Dermatol. 127, 2832-2846 (2007).

35. N. B. Smith, "Perspectives on transdermal ultrasound mediated drug delivery," Int. J. Nanomed. 2(4), 585-594 (2007).

36. H. Tang, D. Blankschtein, and R. Langer, "Effects of low-frequency ultrasound on the transdermal permeation of mannitol: comparative studies with in vivo and in vitro skin," J. Pharm. Sci. 91(8), 17761794 (2002).

37. H. X. Dong, Z. Y. Guo, C. Z. Zeng, H. Q. Zhong, Y. H. He, R. K. Wang, and S. H. Liu, "Quantitative analysis on tongue inspection in traditional Chinese medicine using optical coherence tomography," $J$. Biomed. Opt. 13(1), 011004 (2008).

38. H. Q. Zhong, Z. Y. Guo, H. J. Wei, Z. D. Zhang, C. C. Zeng, J. Zhai, and Y. H. He, "Using low-frequency ultrasound to improve the optical clearing of porcine skin," Proc. SPIE 7280, 72802N (2008).

39. X. Xu, R. K. Wang, and A. El Haj, "Investigation of changes in optical attenuation of bone and neuronal cells in organ culture or three-dimensional constructs in vitro with optical coherence tomography: relevance to cytochrome oxidase monitoring," Eur. Biophys. J. 32(4), 355-362 (2003).

40. J. M. Schmitt, A. Knüttel, A. Gandjbakhche, and R. F. Bonner, "Optical characterization of dense tissues using low-coherence interferometry," Proc. SPIE 1889, 197-211 (1993).

41. V. V. Tuchin, Tissue Optics: Light Scattering Methods and Instruments for Medical Diagnosis, Tutorial Texts in Optical Engineering, vol. TT38, SPIE Press, Bellingham, WA (2000).

42. R. K. Wang, "Modeling optical properties of soft tissue by fractal distribution of scatters," J. Mod. Opt. 47(1), 103-120 (2000).

43. M. J. C. Van Gemert, S. L. Jacques, H. J. C. M. Sterenborg, and W. M. Star, "Skin optics," IEEE Trans. Biomed. Eng. 36(12), 1146-1154 (1989).

44. Z. Z. Mao, Z. Z. Han, X. Wen, Q. M. Luo, and D. Zhu, "Influence of glycerol with different concentration on skin optical clearing and morphological changes in vivo," Proc. SPIE 7278, 72781T (2008).

45. V. V. Tuchin, "Optical clearing of tissues and blood using the immersion method," J. Phys. D 38(15), 2497-2518 (2005).

46. E. I. Galanzha, V. V. Tuchin, A. V. Solovieva, T. V. Stepanova, Q. Luo, and H. Cheng, "Skin backreflectance and microvascular system functioning at the action of osmotic agents," J. Phys. D 36(14), 1739-1746 (2003). 
47. G. A. Husseini and W. G. Pitt, "Ultrasonic-activated micellar drug delivery for cancer treatment," J. Pharm. Sci. 98(3), 795-811 (2009).

48. K. Tachibana, T. Uchida, K. Tamura, H. Eguchi, N. Yamashita, and K. Ogawa, "Enhanced cytotoxic effect of Ara-C by low-intensity ultrasound to HL-60 cells," Cancer Lett. 149(1), 189-194 (2000).

49. K. Tachibana, T. Uchida, K. Ogawa, N. Yamashita, and K. Tamura, "Induction of cell-membrane porosity by ultrasound," Lancet 353(9162), 1409 (1999).

50. S. Mitragotri and J. Kost, "Low-frequency sonophoresis: a noninvasive method of drug delivery and diagnostics," Biotechnol. Prog. 16(3), 488-492 (2000).

51. X. Xu, Q. Zhu, and C. Sun, "Assessment of the effects of ultrasound- mediated alcohols on skin optical clearing," J. Biomed. Opt. 14(3), 034042 (2009).

52. S. Mitragotri, "Sonophoresis: a 50-year journey," Drug Discovery Today 9(17), 735-736 (2004).

53. J. Sundaram, B. R. Mellein, and S. Mitragotri, "An experimental and theoretical analysis of ultrasound-induced permeabilization of cell membranes," Biophys. J. 84(5), 3087-3101 (2003).

54. H. L. Xiong, Z. Y. Guo, C. C. Zeng, L. K. Wang, Y. H. He, and S. H. Liu, "Application of hyperosmotic agent to determine gastric cancer with optical coherence tomography ex vivo in mice," J. Biomed. Opt. 14(2), 024029 (2009). 